\title{
La formación humana desde una perspectiva sociocultural
} Human TRAINING From A SOCIOCULTURAL PERSPECTIVE

\author{
Gustavo A. Segura-Lazcano* \\ Francisco José Argüello-Zepeda* \\ Ivett Vilchis-Torres*
}

* Universidad Autónoma del Estado de México, México Correo-e: gustavoseguralazcano3 @gmail.com

Recibido: 13 de febrero de 2019 Aprobado: 22 de mayo de 2019

Resumen: A partir de los conceptos 'paideia' y 'Bildung' se presenta una reflexión sobre la relación entre educación y formación, así como la importancia de esta última en los procesos de enseñanza, dado que enriquece la instrucción profesional, el desarrollo de valores gregarios, la reflexión crítica y la empatía entre individuos. Se plantea la formación humana y la ciudadanía universal como una forma de enfrentar las circunstancias técnicas y económicas que imperan en el mundo actual y que han llevado a romper el equilibrio socio-ambiental, dando lugar a una crisis civilizatoria.

Palabras clave: filosofía de la educación; ética; formación; crisis ecológica; educación ambiental

Abstract: From the concepts of 'paideia' and 'Bildung' a reflection on the relation between education and training is presented; as well, the importance of the latter in teaching processes is stressed, since it enriches professional training, as it develops gregarious values, critical reflection and empathy between individuals. Human training and universal citizenship are put forward as a way to face the technical and economic circumstances that presently prevail and which have broken the socio-environmental balance, making room for a civilizing crisis.

Keywords: educational philosophy; ethics; training; ecological crisis; environmental education 
Sin aceptación y respeto por sí mismo uno no puede aceptar y respetar al otro, y sin aceptar al otro como un legítimo otro en la convivencia, no hay fenómeno social Humberto Maturana

\section{INTRODUCCIÓN}

La formación humana, en tanto cuestión implicada con las prácticas educativas, suscita en el ámbito universitario importantes reflexiones sobre el sentido social-humanista que debería guiar las profesiones, ciencias y disciplinas cultivadas en nuestras instituciones. Con el afán de participar en este debate ético-académico, el presente artículo aborda algunas perspectivas sobre dicho tema a la vez que resalta su trascendencia entre los actores involucrados.

Se inicia con una problematización de la educación y la formación humana a partir de las aportaciones de diversos autores interesados en la dimensión cultural de la paideia y la Bildung, en la Antigüedad y Modernidad. En seguida, se revisan algunas categorías, como la noción de persona, el ser y su complejidad, dada su incidencia en el desarrollo humano, así como su dimensión ética y profesional. Por último, se hace una reflexión sobre la importancia de la condición ecológica en la formación humana.

\section{RELACIÓN EDUCACIÓN-FORMACIÓN}

La educación es un tema complejo, entre otras razones, por la diversidad de variables y aspectos que intervienen en ella y que están relacionados con la interacción comunicativa, el comportamiento humano, los aprendizajes particulares, las experiencias sociales y las expectativas cognoscitivas de sus diversos actores.

Resulta innegable que todas las sociedades humanas, para subsistir y garantizar la continuidad de su legado, se han ocupado de educar a sus miembros. Al respecto, Emilio Durkheim (1999) señala que las generaciones adultas convocan a las más jóvenes a preservar su cultura y lengua con el propósito de potenciar las capacidades individuales y colectivas, lo que constituye un hecho social de carácter universal.

El tema educativo vincula aspectos cognitivos con experiencias socio-afectivas, además de relacionarse con cuestiones éticas, políticas, económicas y culturales que emanan del entorno. En tal sentido, la educación pretende ser una respuesta adecuada a las circunstancias que envuelven la vida colectiva en cada momento histórico.

Entre las tareas primordiales que se asignan a las prácticas educativas destacan las vinculadas con el propósito de humanizar a los miembros del grupo desde temprana edad, lo cual supone formar individuos con una visión amplia e integral que responda a las expectativas sociales. El papel que desempeñan dichas tareas resulta crucial, dado que "únicamente por la educación el hombre puede llegar a ser hombre. No es sino que la educación le hace ser" (Kant, 1987: 31).

La educación representa la estrategia social dispuesta y aceptada por cada grupo para generar los aprendizajes requeridos. Por medio de reiteradas relaciones comunicativas, mediadas por lenguajes y experiencias, los individuos adquieren saberes y habilidades socialmente necesarios. De acuerdo con Philippe Meirieu (1997), presupone una relación asimétrica, necesaria y provisional entre dos o más seres humanos interesados en renovar su estado de conocimientos.

Desde una visión axiológica, educar implica diferenciar entre la naturaleza de las cosas y "lo que debiera hacerse', lo cual establece una visión normativa de la vida. En efecto, no se escapa de propagar cargas valorativas tendientes a orientar las acciones individuales y colectivas. Por esta razón, "no conlleva únicamente la adquisición de aptitudes, sino también la de los valores, como son el respeto a la vida y la dignidad humana, necesarios para que reine la armonía social en un mundo caracterizado por la diversidad" (UNESCO, 2015: 37). 
Los procesos educativos se traducen en proyectos de humanización. Al enseñar a las nuevas generaciones se asumen representaciones y sentidos de humanidad. Por ello, los impulsores de concepciones educativas de escala global proponen que "la educación [...] ha de reafirmar una visión humanista" (UNESCO, 2015: 36).

La formación humana, de acuerdo con Juan Jacobo Rousseau (2000), ha de ser apreciada como la evolución de la educación del hombre en tanto libertad y plenitud, valores universales que guían la realización del espíritu y el fortalecimiento de la cultura de un pueblo.

Desde la visión poética de J. W. Goethe, la formación humana sugiere emprender un "viaje hacia el conocimiento y la cultura" (J. W. Goethe, en Villegas Durán, 2008: 4), travesía que, sin disponer de un destino preciso, enaltecerá a quienes obtengan las más meritorias experiencias. En tal sentido, afirmamos que constituye un proceso de descubrimientos, cambios, reorientaciones y transformaciones internas en los individuos, como lo advierte el concepto hegeliano de formación, que postula la transformación de la esencia humana (Sopó, 2007).

En relación con el horizonte de reflexión que se despliega a partir del término en cuestión, Hans-Georg Gadamer considera que:

es el concepto donde más claramente se hace perceptible lo profundo que es el cambio espiritual [...] la formación pasa a ser algo muy estrechamente vinculado al concepto de la cultura y designa en primer lugar el modo específicamente humano de dar forma a las disposiciones y capacidades naturales del hombre (2012: 39).

El filósofo advierte la importancia que para la vida individual y colectiva adquiere la formación humana como factor orientador de la cultura. En sentido amplio, se refiere a las actividades y contenidos culturales que modelan a los seres humanos para que puedan llegar a ser lo que su devenir social consiente, sin agotar su potencial. Cualquier formación adquirida o en desarrollo se traduce en el intento por ser alguien, al asumir lo que deriva de cada esfuerzo por alcanzar la meta o el modelo propuesto. Como se verá, resulta tarea primordial de todo ser humano para lograr ser un sujeto real por medio de sus propias capacidades. Los individuos logran afirmarse ante el mundo valiéndose de su raciocinio, corporeidad y sensibilidad, atributos que los mantienen abiertos a sus contextos. Al ser capaces de interpretar e incidir sobre la realidad, se descubren en cada uno de sus actos.

Los procesos de formación hacen que los seres humanos sean sujetos capaces y garantes frente a otros de sus esfuerzos por realizarse y llevar a cabo propósitos asociados. A cada individuo le compete hacerse humano y a cada sociedad se le demanda humanizar a sus colectivos. Por esta razón, se afirma que "la educación es también un proceso por el cual los seres humanos llegamos a ser precisamente eso, humanos" (Tamayo, 2001: 7).

En el campo educativo, la enseñanza resulta un acto de formación trascedente en la medida en que transforma a los actores involucrados. Sus acciones precisan relaciones interpersonales que favorecen determinados fines, por lo que resulta relevante esclarecer el sentido que sustenta el singular encuentro entre seres humanos. En la actualidad, se considera preciso "mantener y aumentar la dignidad, la capacidad y el bienestar de la persona humana en relación con los demás y con la naturaleza” (UNESCO, 2015: 38).

Una vez reconocidos los nexos y la complejidad que origina la relación educación-formación resulta ineludible revisar las aportaciones provenientes de la pedagogía, la filosofía y otras ciencias relacionadas. Al respecto, Fullat Genís (1987) señala que los saberes del campo educativo requieren una visión totalizadora, motivo por el cual sugiere integrar en una misma lectura la pedagogía fundamental, la teoría de la educación y la filosofía de la educación (Cuadro 1). 

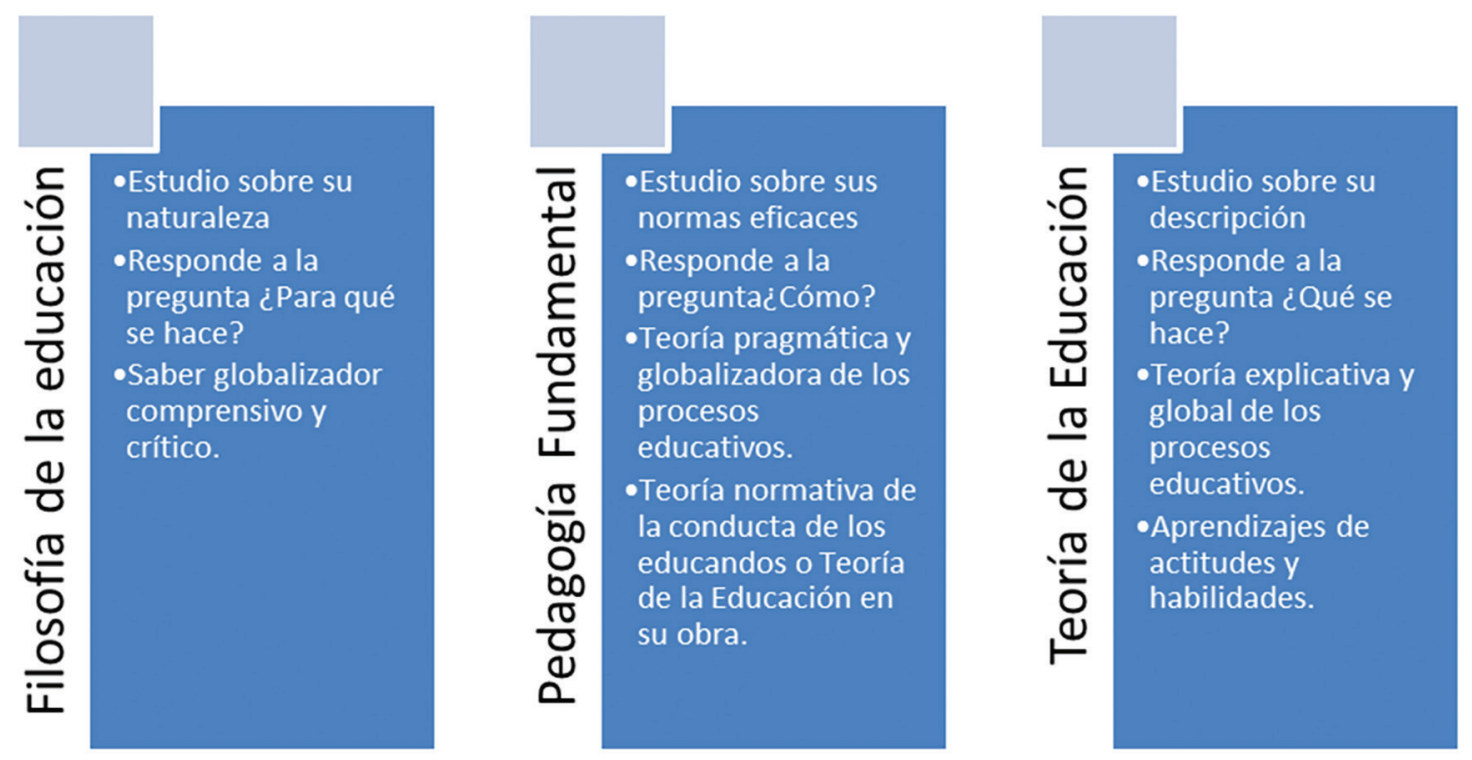

Fuente: Elaboración propia.

\section{Paralelismos entre PAIDEIA y BILDUNG}

Desde sus orígenes, la paideia y la Bildung han estado relacionadas con la educación y la formación. En el caso de la primera, sus fines radicaban en la educación integral, interesada en desarrollar diversos aspectos corporales, emotivos e intelectuales, empleando para tal efecto materias teóricas y prácticas que permitían dotar a las personas de conocimientos y cuidados sobre sí mismas. Al respecto, Platón (2000) destacó la importancia de la educación para los miembros de las polis y la posibilidad de cultivar los atributos propios de cada individuo y sector, lo que podría garantizar mejores resultados al conjunto humano. La Bildung, por su parte, de tradición germana, planteó un proyecto moderno encaminado a la autoformación, por medio del cual la cultura y los ideales colectivos, como la libertad, la democracia y el humanismo, desempeñarían un papel central para la vida social.

En particular, la paideia plantea "un proceso educativo que encamina a los hombres hacia la virtud (areté) entendida como sinónimo de excelencia humana" (Vilanou, 2001: 228). La propuesta requiere apreciarse en el contexto de la Grecia antigua, es decir, de una sociedad que pretendía constituir ciudadanos ejemplares por medio de la inculcación de valores de integridad, entre ellos el esfuerzo propio, la templanza y la solidaridad social. La paideia, de acuerdo con Franco Alirio Vergara M., alude al:
proceso de plasmación del hombre, tanto como individuo como en cuanto pueblo. Paideia y polis son indisolubles, lo mismo que individuo y polis. El individuo es producto de la polis, pero la polis es modelada por las grandes indi- vidualidades que surgen en ella (1989: 153).

Esto significa que la paideia contribuía a formar a los principales actores de la vida pública. Por su parte, Werner Jaeger (2001) señala que en la paideia existe interdependencia entre individuo y sociedad, de modo que resulta incuestionable el papel del Estado como garante de la educación. Sin embargo, la evidencia histórica apunta en favor de algunos sectores privilegiados, 
subordinando el destino de la colectividad a los atributos y virtudes de determinados individuos. El mismo autor menciona la valiosa contribución que hicieron a la paideia destacados intelectuales de la Antigüedad, como Homero - que en sus famosos poemas la Ilíada y la Odisea destaca los valores supremos encarnados por personajes dotados de cualidades sobrehumanas-, así como las aportaciones de los filósofos socráticos —quienes con sus planteamientos y formas simples de vida mostraron congruencia con las virtudes reivindicadas por la paideia, a pesar de que la misma no logró generalizarse en todas las regiones de la Grecia antigua-.

Por otro lado, cabe destacar la fuerza educadora de la tragedia griega, particularmente presente en Esquilo y Sófocles. En las obras de este último aparece el personaje del pedagogo, quien muestra la trascendencia de las tareas encomendadas para educar a los hijos de la nobleza y se distingue de otros maestros que únicamente se ocupan de la instrucción de saberes específicos, tal como lo menciona Juan Delval (1999).

Con respecto a la Bildung, el término se refiere a la "formación de uno mismo para con la cultura en la que uno está inmerso [...] para alcanzar la propia identidad" (Sianes Bautista, 2016: 102). El concepto destaca el papel activo del sujeto para lograr por sí mismo su constitución, lo cual supone una perspectiva de educación suficientemente amplia y capaz de integrar múltiples y sutiles componentes de la cultura vinculados con la humanización de los individuos.

Aunque existan paralelismos y semejanzas entre paideia y Bildung, deben tomarse en cuenta los contextos históricos que les dieron origen. Ambos términos responden a las necesidades sociales propias de su tiempo y abonan a la constitución de individuos y colectivos que fortalecen proyectos y estructuras sociales. En el caso de la paidea, esta noción se hace evidente al inicio de la democracia, forma de organización social con apertura a la participación de los hombres más preparados. La Bildung, por su parte, responde a la condición moderna ilustrada que, en territorios germanos, pretendía unificar la razón y la moral. Al respecto, Conrad Vilanou (2001) sostiene que la Bildung contribuyó a la formación humana de la persona como totalidad.

Horlacher, al estudiar la génesis de este último término, encuentra que "Bildung refiere al objetivo de la realización personal en la vida, aunque es la misma Bildung la que, a su vez, va perfeccionándose a lo largo de esa vida realizada" (2015: 10). De ser correcta su interpretación, el término se refiere a la unificación de las capacidades humanas, como el desarrollo del pensamiento, el carácter y la conciencia en cada sujeto, lo cual lo acredita para su participación activa en la vida sociocultural propia de su contexto.

Más allá de sus enfoques particulares y acentos formativos, tanto la paideia como la Bildung aportaron elementos sumamente valiosos a los modelos educativos y éticos del siglo XX. Sin embargo, su legado para el presente siglo continúa amenazado por los excesos del pensamiento moderno, que incesantemente conducen hacia la especialización y delimitación de la formación, fracturando al ser humano y, al mismo tiempo, relajando el vínculo social. La individualización del proyecto de vida que emerge de las actividades económicas trastoca el sentido gregario de la política y la cultura, cuestiones que al ser instrumentalizadas sirven a los intereses de minorías, lo cual origina una nueva forma de relación entre sujetos.

$\mathrm{Al}$ abandonar el proyecto de formación humana de sus integrantes, las sociedades se deforman y confunden, dando paso a un escenario de coexistencia en condiciones de indiferencia, competencia y rivalidad que reduce la política al ejercicio del poder. Jürgen Habermas afirma que con Maquiavelo "se disuelve el saber práctico de la política en una habilidad técnica” (1975: 28-31). Al dejar de lado los referentes éticos y comunitarios, la política resulta incapaz de garantizar la 
convivencia social al interior de los agrupamientos, lo que ocasiona la creación de individualidades y la pérdida de empatía.

Desde el Renacimiento hasta nuestros días se ha experimentado un viraje de los códigos sociales en favor de relaciones impersonales guiadas por fines utilitarios. El aumento de las transacciones mercantiles ha trastocado la perspectiva de vida de los sujetos al grado de cosificarlos. Esta tendencia materialista actúa de manera negativa en el proceso formativo de las nuevas generaciones, particularmente en lo que se refiere al sentido de colectividad y humanidad histórica. Junto con la pérdida del espíritu gregario, la tecnología, en tanto medio que permite expandir el dominio de los individuos y satisfacer las propias necesidades sin apoyo de otros, ocupa un lugar preponderante en la vida cotidiana. Los efectos del extremo racionalismo social no han pasado inadvertidos, motivo por el cual se denuncia que:

la tekhné que ha pretendido, sobre todo a partir del positivismo, administrar las cosas y también a los hombres, no ha salido muy airosa de su cometido como ha podido verse en este siglo [...] la tékhne comienza a mostrarse inhábil e inexperta en su afán de resolverlo todo. No bastarán la teoría de la educación y la pedagogía fundamental para proporcionar un saber global de lo educante; se requerirá, además, la filosofía de la educación (Fullat Genís, 1987: 8).

Tales señalamientos nos motivan a revisar el fundamento ético de las tareas educativas y los procesos de formación profesional y humana que actualmente se encuentran implicados en las misiones institucionales.

\section{Persona, SER Y COMPLEJIDAD}

Desde el plano etimológico, "el concepto de persona proviene del griego prósopon, rostro o máscara [...] que se utilizaba para ampliar el volumen de la voz en la representación en el teatro" (Sagols, 2006: 48), por tanto, nos remite al personaje que aparece en escena. El término se aplica a cada individuo que enfrenta el reto de convertirse en alguien significativo para otros. Es resultado del suficiente reconocimiento a la condición humana que media la relación entre individuos y permite trascender la propia existencia.

Cualquier persona que adquiere una presencia social resulta influida y moldeada por factores del entorno, elementos y entidades que pueden favorecerle o no a cada momento. Cada sujeto es resultado de un juego de fuerzas externas e internas que sintetizan su modo particular de ser ante los otros. La persona despliega continuamente una noción de sí misma asociada a su conducta, cuestión que la torna un ente irrepetible:

La persona es el individuo humano en cuanto sujeto moral, consciente de sí mismo y de sus actos, capaz de ser responsable de ellos [...] Las principales características de la persona, en tanto ser que se realiza, radican en tres rasgos principales: dignidad, autoconsciencia y autonomía (Sagols, 2006: 48b).

Considerando la compleja dinámica social en la que participa cotidianamente, cada individuo se convierte en actor social responsable de desempeñar uno o varios roles gregarios, motivo por el cual queda obligado a enfrentar las circunstancias que lo envuelven y no pocas veces tendrá que enmascararse para cumplir sus cometidos.

Con base en algunas de las premisas de Immanuel Kant, Lisbeth Sagols (2006) afirma que la persona ha de ser considerada un fin en sí misma, no debiendo ser usada, discriminada, engañada, torturada o sacrificada, dado que tiene dignidad, independientemente de sus méritos individuales y de su posición social.

A partir de esta noción surge la idea de personalidad, que es considerada la manera de ser de cada sujeto, asociada a sus rasgos distintivos, 
a su comportamiento cotidiano y a la manera en que es percibida por los otros. Cada persona unifica numerosos procesos dentro de sí, particularmente relacionados con su cuerpo y psique, los cuales manifiestan la existencia del ser humano que habita y se desarrolla en su interior. Por este motivo, debemos advertir que "la idea del ser implica un cambio, siempre en devenir" (Fromm, 1990: 41). El sujeto nunca termina de ser completamente y con ello se da "el proceso infinito de humanización del hombre” (Kosik, 1967: 74).

La vida humana, considerada como existencia en el mundo, ha motivado constantes interpretaciones y reflexiones filosóficas mediante las cuales se ha conferido sentido a las experiencias y situaciones que los individuos y colectivos enfrentan. Ante la diversidad de argumentos $\mathrm{y}$ visiones que la historia universal registra, los consensos resultan exiguos; sin embargo, la mayoría acepta que lo humano refiere al ser y "el ser significa vivir, permanecer activo, nacer, renovarse, derramarse, moverse, ser productivo" (Fromm, 1990: 73).

Desde el campo de la filosofía existencial, Martín Heidegger (2014) advierte la existencia de prejuicios sobre la noción del ser, ya que constituye el concepto más universal, no es definible y se hace evidente en todo momento. En torno a ello, el afamado pensador propone el Dasein, que corresponde al sujeto, quien vive abierto y en relación con el mundo; ser que, al situarse, deviene y hace del lenguaje su morada. Para el filósofo, humanizarse resulta vital y "es el humanismo: meditar y cuidarse de que el hombre sea humano" (Heidegger, 2000: 3).

Todo sujeto es, ante todo, una presencia anímica que expresa continuidad y experimenta posibilidades de ser desde su interior. Se trata por tanto de un individuo activo que dispone de capacidades cognitivas por medio de las cuales logra tener consciencia de su existencia, así como de los seres y entes que lo rodean. Su relación con el mundo lo define y su vida marca diferencias entre la condición de ser, hacer y tener.
En este punto, hay que hacer notar que "tener se refiere a las cosas [...] ser se refiere a la experiencia” (Fromm, 1990: 91).

La persona, vinculada con la noción de ser, da origen y sustento al propósito de trascender, cuestión que se instaura en su vida, dando lugar a las significaciones y sentidos que proyecta sobre el mundo. Este asunto compete a todo sujeto y amerita la comprensión de los demás. Reconocer el interior de cada persona, su ser, resulta una cuestión fundamental que Erich Fromm destaca al decir "mi yo total, toda mi individualidad, mi mismidad que es única. Como mis huellas digitales, nunca podrá ser plenamente comprendida" (1990: 91).

Los seres humanos, ante la disyuntiva de trascender, proyectan sobre el entorno social sus versiones de formación, algunas de las cuales resultan fácilmente replicadas por la mayoría, mientras otras son enaltecidas por unos cuantos. En general, ningún hombre o mujer, al pretender constituirse en persona, parte de cero, sus aprendizajes fundamentales son inspirados por el legado cultural de aquellos con quienes cohabita, pero finalmente "el ser humano tiene que construir por sí mismo su existencia, descubrir su vocación, su estilo de vida y su profesión" (Malishev, 2003: 8).

Otra dimensión no menos importante del ser asociada con la persona se refiere a su condición de ciudadano. En su origen, la ciudadanía emanaba de la ciudad, siendo atribuida a quienes residían en la urbe y estaban adscritos al agrupamiento o colectividad civil. Por definición, los ciudadanos gozan de derechos y obligaciones al ser integrantes de núcleos humanos con capacidad de organización política.

Aunque al principio la ciudadanía era exclusiva de las clases privilegiadas que presidían las incipientes naciones, con el paso del tiempo y la expansión del dominio de estos Estados, diversos pueblos y territorios terminaron siendo agregados a ellos, adquiriendo las lenguas, culturas y símbolos que los regían. 
Desde la Antigüedad, la humanidad ha tenido que lidiar con criterios de inclusión y exclusión social ligados a la noción de ciudadanía; por ejemplo, por siglos los esclavos no contaron con ella y, en consecuencia, no participaban de ninguna forma en la toma de decisiones del colectivo civil. Toda ciudadanía impone una membresía identitaria que favorece la cohesión social. Gracias a ella, los individuos adquieren atributos políticos que demandan formación. Por tanto, se reconoce que desde los inicios de la civilización "la educación fue condición indispensable de la ciudadanía [...] mas no suficiente" (Meyenberg Leycegui, 2000: 12).

La ciudadanía es un componente fundamental para la organización de las naciones modernas; sin embargo, ha sido identificada como limitativa, ceñida al marco legal propio de cada país. De alguna manera, este concepto contrasta y resignifica el proyecto de humanización que, más allá de lo estrictamente comercial, esboza la globalización. Algunos autores proponen emplear la categoría 'ciudadanía global', de modo que los seres humanos del siglo XXI adquieran nuevos referentes espaciales y culturales sin estar sujetos al alcance de las lenguas, fronteras y patrimonios. Esta utopía aspira al despertar de una conciencia común y de pertenencia al colectivo mundial que haga de todos los individuos miembros distinguidos de la humanidad.

Ser ciudadanos del mundo supone crear nuevos vínculos entre los pueblos, alentar visiones incluyentes y enfatizar la fraternidad que pudiera guiar e identificar a nuestra especie. Pensadores prestigiados, como Paulo Freire, Martha Jalali Rabbani y Edgar Morin, han señalado la importancia de impulsar una educación en favor de la ciudadanía global que establezca condiciones de diálogo entre individuos y colectivos, e instaure, al seno de la vida gregaria, los principios de equidad y diversidad humana.

En particular, Freire (1972) considera imprescindible superar la visión bancaria de la formación y alentar una educación emancipadora capaz de generar conciencia sobre los problemas comunes del mundo actual. Por su parte, Martha Jalali Rabbani (2001) desarrolla la idea de unidad humana como un escenario situado más allá de las diferencias particulares. La pensadora aspira a que nuestra especie asuma una condición de interdependencia y practique valores máximos, entre ellos la libertad, el respeto y la solidaridad. Edgar Morin (1995) postula el principio dialógico como un medio que permite develar la realidad común e insoslayable. Al asumir la dialógica propia del pensamiento complejo, el filósofo considera posible impulsar una conciencia planetaria sustentada en una educación en valores. En general, los autores mencionados destacan la importancia de humanizar a los individuos y colectivos, advirtiendo los efectos perniciosos que derivan de asumir irreflexivamente un progreso técnico carente de limitaciones éticas. Sus planteamientos nos recuerdan que "la sociedad industrial desprecia la naturaleza y todas las cosas que no están hechas por máquinas" (Fromm, 1990: 27).

Tomando en cuenta la complejidad de lo humano, Mijail Malishev (2003) sugiere incursionar en la perspectiva del ser multifacético. Su visión incita a considerar todas las dimensiones que envuelven la vida de la persona y que le permiten efectuar diversas tareas y desarrollar sus capacidades. El autor asevera que:

el hombre es un ser único en su género [...] tiene razón, está dotado de lenguaje simbólico, se da cuenta de su muerte, crea el mundo de la cultura y es capaz de reflejar en su conciencia una variedad infinita de propiedades del universo (Malishev, 2003: 13).

Cada individuo es finalmente un ser complejo, siempre en desarrollo, cuya existencia no se limita únicamente al campo de la razón, pues está igualmente conformado por sus pasiones. Por medio de sus atributos y capacidades, los sujetos despliegan cotidianamente la actividad anímica que les permite realizarse en los ámbitos en los 
cuales participan. Para tal efecto, las personas emprenden procesos de formación acompañadas de algunos miembros de la especie. Las orientaciones que reciben, diversas y no pocas veces contradictorias, contribuyen a que los individuos y colectivos den ejemplos de sabiduría, heroísmo, crueldad y fanatismo. La formación humana, por tanto, resulta un elemento fundamental para el desarrollo de las sociedades.

\section{LA FORMACIÓN Y LA ACTIVIDAD PROFESIONAL}

Debido a la expansión de las capacidades institucionales y a la diversificación de los procesos que constituyen a los individuos, la línea divisoria entre formación humana y educación ciudadana resulta imperceptible. Por tal motivo, y considerando su relevancia, se requiere tomar en cuenta los factores cardinales que humanizan a las personas y se encuentran asociados con las tareas de instrucción.

A diferencia de la educación no formal, la instituida o formal define perfiles y sistemas de formación ceñidos a finalidades decretadas por los órganos que gobiernan cada sociedad. En el ámbito de los estudios superiores, dichos sistemas son responsables de brindar la formación profesional que requiere cada generación de acuerdo con la misión encomendada, tarea en la cual se integran los componentes laboral y social. Esto conlleva a que los egresados puedan desempeñarse eficazmente y hacerse cargo de los trabajos requeridos.

En cuanto a los procesos cognitivos asociados a la formación profesional, conviene diferenciar los orientados a la asimilación de las técnicas propias del campo laboral disciplinario de aquellos vinculados a la socialización entre pares y demás miembros del grupo donde se realizan las actividades. A lo largo de su vida, las personas enfrentarán el reto de explorar y conocer el mundo material que las circunscribe, adquiriendo ciertos dominios sobre el mismo, pero a la vez deberán asumir el desafío de comprenderse y comprender a los seres que las acompañan en cada etapa de su existencia.

Los procesos de asimilación y socialización llevados a cabo acrecentarán el conocimiento de los sujetos sobre su entorno. Sus saberes se convertirán en referentes importantes para la mayoría, al grado de que habrán de conferir sentido a sus principales experiencias de vida. Entender suficientemente el mundo en el que actúa constituye una de las principales estrategias de sobrevivencia de nuestra especie: "Conocimiento significa que el individuo hace suyo lo que aprende, sintiéndolo, experimentando consigo mismo, observando a los demás y, finalmente, llegando a una convicción” (Fromm, 1989: 151).

El saber adquirido permite entender las situaciones y tomar decisiones en favor del ser pensante. Sin embargo, no siempre dicho resultado está garantizado, dado que los fenómenos del mundo traicionan constantemente nuestra apreciación y las formas observadas encubren sus contenidos: "El conocimiento empieza con la conciencia del engaño de lo que perciben nuestros sentidos [...] nuestro panorama de la realidad física no corresponde a lo que realmente es [...] el conocimiento empieza con la destrucción de las ilusiones" (Fromm, 1990: 53).

Comprender de mejor manera las cosas y los seres resulta un asunto problemático para cualquier persona, más aún si se considera que las situaciones sociales ameritan resolverse sin violencia de por medio. La labor diaria de percibir el mundo requiere ser asumida con interés y mesura, dado que cada experiencia, resulte o no exitosa, constituye al individuo.

La formación profesional, en tanto habilitación por conocimiento, limita la actuación a campos específicos de trabajo. En cambio, la formación humana y social incita a los individuos a interactuar con otros miembros del grupo en torno a intereses y valores comunes. Así, permite a la mayoría participar en las dinámicas y contextos propios de la vida colectiva asociada con 
los campos de actuación que han sido concertados. La formación social y humana vinculada a las experiencias profesionales contribuye al proceso de introspección por medio del cual el sujeto accede al conocimiento de sí mismo. Esto favorece la definición del sentido existencial que resignifica las labores y experiencias cotidianas.

Los procesos de socialización e introspección constituyen el principal sustrato para la formación humana en la medida en que ambas dinámicas vigorizan y profundizan la humanización de las personas, un tema crucial que en las sociedades actuales no se ha discutido a profundidad, poniendo en riesgo la sobrevivencia de la especie en su conjunto.

La formación humana es resultado de las mejores experiencias y aprendizajes que derivan de las relaciones interpersonales en diversos tiempos entre colectivos. Recordemos que la humanización "es un proceso en el cual los participantes se dan unos a otros aquello que aún no tienen [...] el reconocimiento de lo humano por lo humano es un imperativo en la vía de maduración personal de cada uno" (Savater, 2006: 53). La formación humana no puede ser asumida tan sólo como contenido teórico dado que permanece supeditado a las vivencias personales y a la reflexión crítica que resignifica los contextos y abre las perspectivas de vida gregaria.

Desde una visión educativa e institucional, se requiere sustentar la formación humana en condiciones de diálogo, por medio del cual los partícipes logren compartir sus experiencias más sentidas y adquieran conciencia de la realidad que envuelve sus vidas.

Independientemente de los modelos sociales que han servido como referencia a la mayoría de los pueblos y que fueron determinados por hitos históricos, el proyecto de formación humana invita a obtener la mejor versión posible de cada persona. Humanizar implica ampliar la conciencia en torno al curso de la vida y, siendo apreciada desde la propia, convoca a hacerse responsable de las acciones que propician la convivencia.
La formación humana complementa a la profesional, le confiere significados valiosos, la enriquece y le añade proyección social. Cualquier desempeño puede cuestionarse si carece de empatía e intención solidaria. La práctica médica, por ejemplo, siendo indiferente al dolor humano debido a la falta de solvencia económica del paciente, terminaría denigrando al individuo mejor preparado. A falta de sentimientos fraternos, las actividades profesionales se tornan labores distantes, socialmente precarias y sin propósitos relacionales, lo que las debilita y torna acciones intrascendentes. Despreciando y cosificando a los demás, los profesionales se desvalorizan, se cosifican y vuelven infames sus labores.

Los esfuerzos por lograr la empatía y comprensión entre individuos nunca declinan del todo. En cada época quienes han dirigido con integridad a grupos e instituciones también nos han legado modelos de humanización. Incluso tratándose de una cuestión ideal y debatible, la pesquisa de hombres renovados y superiores se mantiene latente en buena parte de los sistemas de valores gregarios que configuran las pautas sociales. Diversos proyectos modelan la conducta de los individuos, los orientan a formas particulares de convivencia social. Los abusos de algunos y la falta de valentía o entendimiento de otros no han anulado los anhelos y aspiraciones de la mayoría; por el contrario, han motivado el surgimiento de seres extraordinarios que, sin apego a los valores señalados, con su ejemplar actuación construyeron referentes sólidos y universales.

Los tiempos actuales resultan confusos, complejos y contradictorios; los modelos que se consideraban infalibles están siendo rechazados por numerosos grupos, la mayoría desencantados de la modernidad. Al ser víctimas de la desconfianza, las personas reniegan de cualquier paradigma que pudiera ser señalado como superior a los existentes. Los sujetos más críticos señalan lo absurdo de pretender perfeccionar a todos los individuos a partir de arquetipos que nadie 
puede encarnar. Si la humanidad se funda en la diversidad, la multiplicidad de maneras de ser constituye su esencia.

\section{LA FORMACIÓN PROFESIONAL INTEGRADORA}

Al formar parte de cierta utopía educativa, los colectivos universitarios afirman asiduamente que la formación profesional requiere ser integral. Su premisa parte de considerar las múltiples capacidades humanas, sean físicas, emocionales, mentales o espirituales, así como los diversos ámbitos de actividad social en los que participan los individuos y que multiplican los conocimientos y habilidades demandadas por las sociedades altamente tecnificadas del siglo XXI.

La integralidad de todos los universitarios se constituye en un propósito sugerente, acorde con la complejidad del individuo, aunque poco factible ante la formación especializada que reclama la división social del trabajo y el bajo interés que, entre la mayoría, despierta un proyecto de tal naturaleza. Por tanto, cada vez resulta más evidente la sentencia de Erich Fromm: el hombre siempre muere antes de haber realizado todas sus potencialidades (Rovaletti, 1985).

Inducidos por la dinámica social propia de su tiempo, los seres humanos optan por llevar a cabo acciones en favor o en contra de los miembros de su especie, en particular de quienes consideran sumisos. Los efectos provocados por sus actos no siempre les resultan evidentes, pero sin duda acarrean responsabilidades.

Desde una visión eco-sistémica, María Novo y M. Ángeles Murga (2010), junto con otros intelectuales del siglo XXI, han propuesto asociar el concepto de ciudadanía planetaria al de educación ambiental con la intención de formar una conciencia responsable de la biodiversidad vinculada con los entornos naturales. Esto llevaría a generalizar los cuidados que el planeta requiere debido al avance de los sistemas de producción, garantizando el curso de la vida en su conjunto.

\section{CONDición HUMANA Y ECOLÓGICA}

La continuidad de la vida humana como especie animal se encuentra supeditada a los recursos y condiciones existentes en el territorio geográfico. Por muy avanzada que sea la tecnología de que disponga cualquier grupo, hombres y mujeres permanecen condicionados por los bienes que ofrece la naturaleza al grado de que los procesos biológicos pueden fortalecerlos de forma temporal o deteriorarlos definitivamente.

el estudio comparado del comportamiento animal y humano ha puesto de manifiesto grandes semejanzas, y algunas diferencias [...] la diferencia está en que el hombre, guiado por los demás, por esa acumulación social de conocimientos que se le transmiten tanto de forma práctica y directa como por diferentes medios simbólicos, puede ir elaborando modelos del ambiente que son mucho más variados y precisos que los de los animales (Delval, 1999: 9).

La subsistencia de los seres humanos depende en buena medida de mantener estables las relaciones y condiciones de intercambio energético y anímico con la naturaleza que les rodea. Al respecto, las circunstancias eco-sistémicas dan cuenta de la organización y complejidad que encierran los procesos que sustentan la biodiversidad y que posibilitan la vida humana, como el papel que desempeñan las relaciones de colaboración y competencia entre los miembros de la especie (Morin y Kern, 1993).

Más allá de los aspectos físico-biológicos que determinan la vida humana, los miembros de nuestra especie configuran escenarios propios que favorecen la interacción,
comparado con los demás animales, el hombre no sólo vive en una realidad más amplia, sino en una nueva dimensión de la realidad [...] ya no vive en un puro universo físico, sino en un 
universo simbólico. El lenguaje, el mito, el arte y la religión constituyen partes de este universo (Cassirer, 1968: 13).

Desde la era neolítica, los seres humanos se han ocupado de expandir su dominio sobre los entornos naturales, logrando someter numerosos fenómenos a su voluntad, pero sin lograr, hasta el momento, sustituirlos de forma definitiva. El avance del conocimiento sobre las formas y energías de la naturaleza ha jugado un papel definitivo en este proceso, sin embargo, en su afán de dominación el hombre ha provocado daños colaterales que han terminado por afectarlo.

Conformada por las manifestaciones que se despliegan en nuestro planeta y que ha dado origen a diversas formas de vida que evolucionan a la par de la nuestra, la naturaleza ha edificado un extraordinario y frágil entramado de relaciones vitales, por medio de las cuales tanto los organismos como los demás componentes asociados establecen vínculos de interdependencia al grado de que cualquier alteración sobre los mismos genera efectos significativos sobre el conjunto.

Tomando en cuenta la biodiversidad y el comportamiento singular de las especies, resulta imposible sostener la teoría de la vileza congénita propia de ciertas poblaciones. Algunos comportamientos atípicos, por grotescos que nos parezcan, están encaminados a garantizar la sobrevivencia de los organismos, los cuales, con o sin colaboración de sus similares, luchan por perdurar en un equilibrio ecológico supeditado a las fuerzas de la naturaleza.

El agotamiento de los recursos naturales no renovables y la extinción de numerosas especies, resultado de los modelos civilizatorios implantados en los últimos dos siglos, generan fuertes desequilibrios en el complejo y laborioso tejido de la biodiversidad que por milenios ha existido. Los efectos negativos están a la vista de todos: el cambio climático, la contaminación hídrica, las migraciones de organismos, la deforestación, el desabasto y los nuevos padecimientos son sólo la manifestación de la acción humana que carece de límites y objetivos reflexivos. La destrucción de la naturaleza que el hombre ha emprendido tiene historia:

La crisis ambiental se hace evidente en los años sesenta, reflejándose en la irracionalidad ecológica de los patrones dominantes de producción y consumo, y marcando los límites del crecimiento económico. De esta manera, se inicia el debate teórico y político para valorizar a la naturaleza e internalizar las 'externalidades socioambientales al sistema económico' (Leff, 1998: 15-16).

El capitalismo ha resultado un modelo económico capaz de generar grandes riquezas para la humanidad, pero en la misma proporción reclama enormes cantidades de recursos naturales y un alto consumo energético. El crecimiento demográfico a nivel mundial se explica por el dominio técnico alcanzado por los miembros de nuestra especie. Las operaciones llevadas a cabo por tales medios han incrementado los requerimientos materiales asociados con los satisfactores de corto y mediano plazo que configuran el modo actual de vida.

Las pautas culturales y estructuras sociales que prevalecen han alterado la condición y el equilibrio eco-sistémico. Por ello, requerimos de nuevas pautas socioculturales y éticas, respaldadas en conocimientos ambientales, que eviten el colapso de la vida en el planeta. Una visión ecológica compartida por todos contribuiría a resarcir los procesos bióticos y a moderar el consumo urbano y sus impactos sobre los ecosistemas próximos y lejanos.

En aras de avanzar hacia un modelo de desarrollo alterno que no ponga en peligro la vida humana en el planeta, la propuesta de sustentabilidad, a partir del Informe Brundtland realizado en 1987, ha dado origen a polémicos planteamientos civilizatorios. Nuevas 
profesiones, investigaciones, normatividades, inventarios, desarrollos tecnológicos y agencias encausadas hacia objetivos de protección ambiental han incidido en distintas actividades productivas y consuntivas en cada una de las regiones del orbe.

A pesar de los esfuerzos de los actores más comprometidos, hasta el momento no se ha logrado disminuir el ritmo y, menos aún, el impacto que deriva del crecimiento de la población mundial. Es así que:

La problemática ambiental emerge como una crisis de civilización: de la cultura occidental; de la racionalidad de la modernidad; de la economía del mundo globalizado. No es una catástrofe ecológica ni un simple desequilibrio de la economía. Es el desquiciamiento del mundo al que conduce la cosificación del ser y la sobreexplotación de la naturaleza; es la pérdida del sentido de la existencia que genera el pensamiento racional en su negación de la otredad (Leff, 2004: ix).

Sin duda, la evolución biológica le ha dado a nuestra especie condiciones privilegiadas; sus capacidades físicas, emocionales e intelectuales le han permitido transformar radicalmente el entorno. Pese a ello, los seres humanos, en su mayoría, no han adquirido consciencia plena de las complejas relaciones que guarda su existencia con la biodiversidad y los ambientes naturales de los cuales forman parte activa.

El saber acumulado durante siglos no ha logrado frenar la acometida en contra de diversas formas de vida, motivo por el cual las personas continúan careciendo de una perspectiva realmente planetaria. En torno a ello, Erich Fromm advierte: "si la humanidad se extingue a sí misma, no será por la maldad intrínseca del corazón del hombre; será por su incapacidad para despertar a las alternativas realistas y sus consecuencias" (1989: 169).

\section{REFLEXIONES FINALES}

Desde la perspectiva cultural, las tareas educativas y formativas constituyen a los sujetos en personas, incidiendo significativamente en su presencia y desempeño social. La alternancia de procesos liberadores y adaptativos define las condiciones generales sobre las cuales se despliega la vida cotidiana en términos de diferencias y similitudes entre individuos.

Tanto paideia como Bildung continúan siendo referentes educativos para la sociedad moderna, reiterando sus ideales de perfeccionamiento y realización personal, que se asocian con los saberes requeridos. Sin embargo, los tiempos actuales, donde las capacidades laborales e intelectuales se supeditan a los avances tecnológicos, nos llevan a reflexionar sobre el sentido humano, implícito en la necesidad imperiosa de configurar un ser propio y, a la vez, común con otros.

El individuo responde a la complejidad que se origina en su interior, proceso incesante que, de manera consciente o inconsciente, genera como resultado una personalidad que se proyecta sobre el mundo y se alimenta de las circunstancias que produce el conjunto humano.

Dadas las dificultades que actualmente enfrentamos, se hace necesario revalorar la formación humana como un elemento central de las tareas educativas con el fin de fortalecer los vínculos fraternos al interior de la sociedad, haciendo que las profesiones y vocaciones incidan en un compromiso colectivo con el devenir humano y planetario.

La dinámica educativa y cultural que prevalece continúa relegando los contextos medioambientales y sociales, lo cual ha favorecido el avance del individualismo en la sociedad y una visión fragmentaria de la realidad. Esto ha reducido la capacidad de las personas para comprender la complejidad de los fenómenos emergentes y, junto con ello, la posibilidad de respuesta a los mismos sustentada en amplios consensos. 


\section{REFERENCIAS}

Cassirer, Ernst (1968), Antropología filosófica. Introducción a una filosofía de la cultura, México, FCE.

Delval, Juan (1999), Los fines de la educación, Madrid, Siglo XXI.

Durkheim, Emilio (1999), Educación y sociología, México, Diálogo.

Freire, Paulo (1972), La educación como práctica de la libertad, Buenos Aires, Siglo XXI.

Fromm, Erich (1989), El corazón del hombre, México, FCE.

Fromm, Erich (1990), iTener o ser?, México, FCE.

Fullat Genís, Octavi (1987), "Filosofía de la educación: concepto y límites”, Filosofia de l'Educació, núm. 11, pp. 5-15.

Gadamer, Hans-Georg (2012), Verdad y método, Salamanca, Sígueme.

Habermas, Jürgen (1975), Teoría y praxis, Oviedo, Universidad de Oviedo.

Heidegger, Martín (2000), Carta sobre el humanismo, Madrid, Alianza Editorial.

Heidegger, Martín (2014), Ser y tiempo, Madrid, Trotta.

Horlacher, Rebekka (2015), Bildung, la formación, Barcelona, Octaedro.

Jaeger, Werner (2001), Paideia: los ideales de la cultura griega, México, FCE.

Jalali Rabbani, Martha (2001), La educación para la ciudadanía mundial, Toluca, UAEM.

Kant, Immanuel (1987), Pedagogía, Madrid, Akal.

Kosik, Karel (1967), Dialéctica de lo concreto. Estudio sobre los problemas del hombre y el mundo, México, Grijalbo.

Leff, Enrique (1998), Saber ambiental. Sustentabilidad, racionalidad, complejidad, poder, México, Siglo XXI.

Leff, Enrique (2004), Racionalidad ambiental, la reapropiación social de la naturaleza, Madrid, Siglo XXI.

Malishev, Mijail (2003), El hombre: un ser multifacético. Antología de antropología filosófica, Toluca, UAEM.

Meirieu, Philippe (1997), "Praxis pédagogique et pensée de la pédagogie”, Rerue Française de Pédagogie, núm. 120, pp. 25-37.

Meyenberg Leycegui, Yolanda (2000), "Ciudadanía: cuatro recortes analíticos para aproximarse al concepto", Perfiles Latinoamericanos, núm. 15, pp. 9-26.

Morin, Edgar y Anne Brigitte Kern (1993), Tierra Patria, Buenos Aires, Nueva Visión.

Morin, Edgar (1995), Introducción al pensamiento complejo, Barcelona, Gedisa.

Novo, María y M. Ángeles Murga (2010), "Educación ambiental y ciudadanía planetaria”, Revista Eureka sobre Enseñanza y Divulgación de las Ciencias, núm. 7, pp. 179-186.

Platón (2000), La república, Madrid, Edimat Libros.

Rousseau, Juan Jacobo (2000), Emilio o la educación, Buenos Aires, El Aleph Editores.

Rovaletti, María Lucrecia (1985), Erich Fromm. Pensamiento y obra, Buenos Aires, AZ Editora.

Sagols, Lisbeth (2006), Ética y valores II, México, McGraw Hill Interamericana.

Savater, Fernando (2006), El valor de educar, Barcelona, Ariel.
Sianes Bautista, Alicia (2016), “'Bildung': concepto, evolución e influjo en la pedagogía occidental desde una perspectiva histórica y actual", Revista Española de Educación Comparada, núm. 30, pp. 99-111.

Sopó, Ángel María (2007), "El concepto hegeliano de formación. Una aproximación”, Logos, núm. 12, pp. 39-47.

Tamayo, Martín E. (2001), Erich Fromm y la educación, México, Universidad Pedagógica Nacional, disponible en: http://200.23.113.51/pdf/18554.pdf

UNESCO (2015), Replantear la educación. ¿Hacia un bien común mundial?, Sint Pieters Leeuw, Bélgica, Ediciones UNESCO.

Vergara M., Franco Alirio (1989), "La Paideia Griega”, Universitas Philosophica, núm. 11-12, pp. 153-168.

Vilanou, Conrad (2001), "De la Paideia a la Bildung: hacia una pedagogía hermenéutica”, Revista Portuguesa de Educação, vol. 14, núm. 2, pp. 2-16.

Villegas Durán, Luz Amparo (2008), "Formación: apuntes para su comprensión en la docencia universitaria", Profesorado: Revista de Curriculum y Formación del Profesorado, vol. 12, núm. 3, pp. 1-14. 
Gustavo A. Segura Lazcano. Profesor-Investigador del Centro de Investigación Multidisciplinaria en Educación de la Universidad Autónoma del Estado de México (UAEM), México. Adscrito al Sistema Nacional de Investigadores. Es Doctor en Educación por la Escuela Libre de Ciencias Políticas y Administración Pública de Oriente, México. Es líder del cuerpo académico Educación y Sociedad. Entre sus publicaciones están: "Desempleo juvenil y matrícula universitaria en México itransición al desarrollo o esquizofrenia?" (Elementos, núm. 101, 2006), en coautoría con Eduardo Loría, y el capítulo "Los entornos de innovación y responsabilidad social para la universidad pública en condiciones de globalidad" (en Humanismus und Ethik als Brücke zwischen den Kulturen, 2013).

(D) https://0000-0002-1038-7806

Correo-e: gustavoseguralazcano3@gmail.com

Francisco José Argüello Zepeda. Profesor-Investigador del Centro de Investigaciones Multidisciplinarias en Educación de la UAEM, México. Adscrito al Sistema Nacional de Investigadores Nivel I. Doctor en Antropología por la Universidad Laval, Canadá. Sus líneas de investigación versan sobre antropología rural, educación ambiental y ética económica. Entre sus publicaciones se encuentran: Educación ambiental y globalización: Modelos interdisciplinarios en la UAEM (UAEM, 2004), y La privatización de la industria azucarera mexicana y su impacto social, (UAT/COTACYT, 1998).

(D) https://0000-0003-4673-3026

Correo-e: farguello2010@hotmail.com

Ivett Vilchis Torres. Profesora de Tiempo Completo del Centro de Investigación Multidisciplinaria en Educación de la UAEM, México. Es Maestra en Comunicación y Tecnologías Educativas por el Instituto Latinoamericano de Comunicación Educativa, México. Actualmente, realiza estudios doctorales en la Universidad de San Luis Potosí. Forma parte del cuerpo académico Educación y Sociedad. Sus líneas de investigación son educación socio-ambiental y nuevas tecnologías.

(D) https://0000-0003-0197-626X

Correo-e: ivilchist@uaemex.mx 